\title{
Applying Adaptive Neuro-Fuzzy Model for Bankruptcy Prediction
}

\author{
Tayebeh Zanganeh \\ Young Researchers Club, \\ Hamedan Branch, Islamic Azad \\ University, Hamedan, Iran.
}

\author{
Meysam Rabiee \\ Department of Industrial Engineering, \\ K. N. Toosi University of Technology \\ Tehran, Iran
}

\author{
Masoud Zarei \\ Department of Accounting, Islamic \\ Azad University \\ Hamadan, Iran
}

\begin{abstract}
This study demonstrates effectiveness of ANFIS in bankruptcy prediction which has received a few attentions in the previous bankruptcy studies. A data set consisting of financial ratios of 136 matched bankrupt and non-bankrupt firms in Tehran Stock Exchange (TSE) during 1997-2008. Moreover, two different procedures are used for selecting the predictive variables. The first procedure is using T-statistic feature selection method. Another one is not using any feature selection method. In second procedure, just examination of former researches is used for selecting the predictive variables. The resulting models are estimated with three different data set partitioning patterns. Analysis of empirical results indicates: (1) The ANFIS model outperforms Logistic Regression (LR) model in both training and testing samples. (2) The subset of frequent variables in the former literature yields better prediction models rather than variables are selected based on T-statistic feature selection method.
\end{abstract}

\section{General Terms}

Neural network, fuzzy systems, prediction

\section{Keywords}

Bankruptcy Prediction; ANFIS; Logistic Regression; Tehran Stock Exchange (TSE); Feature selection

\section{INTRODUCTION}

Formal analysis on bankruptcy prediction has been started since 1932, and still continues to attract intense interest among academics, practitioners and regulators [1], Since the pioneering financial ratio model conceptualized by Beaver [2], bankruptcy prediction models, such as the multivariate analysis technique by Altman [3], the linear probability model by Myer and Pifer [4] and the logistic regression model by Ohlson [5] have been much-developed. Two last mentioned models give a crisp relationship between explanatory and response variables of the given data set from a statistical view point and not assume multivariate normality [6].

In recent years, much attention is given to the choice of methodology to overcome the shortcoming and restrictive assumptions of primitive statistical methods. Artificially intelligent expert system techniques which are very efficient for searching an unknown linear or non-linear pattern in a massive data set have been developed. One of the most popular of these techniques is artificial neural networks [7]. Many studies have shown that artificial neural networks (ANN) are more accurate, adaptive and robust in comparison with traditional statistics models [8, 9, 10, and 11]. A review of applications of neural networks in bankruptcy prediction can be found in Atiya [12]. In spite of ANN being good for modeling nonlinear systems they suffer from their inability to explain the steps used to make decisions and incorporate rules in their architecture [13].

Identification of specific factors or their combination that leads to unfavorable forecast is very important to managers. That is, managers can make more use of conventional or fuzzy interpretable IF THEN rules rather than neural networks [14].

Since its introduction in 1965 by zadeh [15], fuzzy set theory received considerable attention, not only in the scientific community but also in the industry. The purpose of fuzzy logic is to map one space (input) to another (output) with relative precision (using ifthen rules). Some researchers have used fuzzy rule-based systems for bankruptcy prediction such as [16].

Since fuzzy systems do not have much learning capability, it is difficult for human operator to tune the fuzzy rules and membership functions from the training data set. Fuzzy modeling, along with other techniques especially neural network, is recognized as a powerful tool that can facilitate the effective development of prediction models. The rule-based nature of fuzzy models allows better use of information expressed in the form of natural language statement and consequently, makes the models interpretation easier $[19,17]$.

There are three different approaches to combining neural networks and fuzzy systems [19]: (1) Concurrent Neural-Fuzzy Model: in this model, fuzzy system is used either before or after neural network. The neural network does not change any parameters in the fuzzy system. (2) Cooperative neuro-fuzzy Model: in this model, a neural network is used to learn certain parameters of fuzzy sets, fuzzy rules or weights of the fuzzy system. The result is a pure fuzzy system. (3) Hybrid neuro-fuzzy Inference system: in this model, the neural network and fuzzy system are no longer separated in this model. This research uses a hybrid neuro-fuzzy model.

Adaptive-Network-Based Fuzzy Inference System (ANFIS) proposed by Roger Jang [20] is one of the ways to integrate neural networks and fuzzy systems. ANFIS is the class of adaptive networks which are functionally equivalent to fuzzy inference and has advantages of neural network and fuzzy logic [20].One important feature of the ANFIS is that is adaptable; the membership function parameter can adapt and change within the learning procedure.

Although this effective approach was first introduced in early $1993 \mathrm{~s}$, it has been applied to bankruptcy prediction just in few studies so far.

Ravi Kumar and Ravi [17] applied ANFIS model within ensembles created model. A set of seven classifiers was applied: adaptive neuro fuzzy inference system (ANFIS), support vector machine (SVM), four types of RBF networks, and MLP. The majority voting rule has 
been used to aggregate ensemble members. Their results indicate that ANFIS, Semi-Online RBF2 and MLP are the most important classifiers among the seven classifiers employed in their study.

The correct classification rate of ANFIS model has been compared with Altman Z-score by Purvinis et al [14]. They showed that the relation between bankruptcy forecast and considered financial ratios is complicated and nonlinear. As they expected ANFIS outperformed Altman Z-score model. Their proposed ANFIS model showed that percentage of right failure and success predictions is $80 \%$.

Advantages of ANFIS over statistical, neural network and fuzzy system and the fact that this method has not been subject of enough empirical studies in bankruptcy prediction studies make further empirical research on this issue quite necessary.

This paper contributes in this topic in two aspects. First, we apply ANFIS structure for bankruptcy prediction of the Tehran Stock Exchange (TSE) firms and compare the performance of ANFIS with logistic regression (LR) which is widely used statistical method for binary classification problem. Second, we hybrid ANFIS and LR models with two following alternative feature selection procedure methods and compare the results based on each of them: (1) Selection the most frequent variables in the former bankruptcy prediction literature. (2) Selection variables by T-statistic method.

The variables selected by T-statistic method show to be more stable and accurate in prediction of bankruptcy than other statistical feature selection methods [21].

Therefore, T-statistic method is applied for selecting predictive variables in this study.

The remaining parts of the paper are organized as follows. Section 2 describes architecture of ANFIS and applied statistical methods. Section 3 describes our proposed prediction model. Empirical results are presented in sections 4 . Finally, section 5 provides a summary and conclusion.

\section{DESCRIPTION OF THE APPLIED METHODS}

\subsection{ANFIS and its architecture}

ANFIS is a multilayer network- based neural fuzzy system. For illustration, a fuzzy inference system consisting of five layers of adaptive network with two inputs $\mathrm{x}$ and $\mathrm{y}$ and output $\mathrm{z}$ is shown in Fig. 1.

For the first-order TSK fuzzy model, a typical rule set with two fuzzy "if-then rules" could be as following:

$$
\begin{aligned}
& \text { Rule1: If } x \text { is } A_{1} \text { and } y \text { is } \mathrm{B}_{1} \text {, then } \mathrm{f}_{1}=p_{1} x+q_{1} y+r_{1} \\
& \text { Rule2: If } x \text { is } A_{2} \text { and } y \text { is } B_{2} \text {, then } \mathrm{f}_{2}=p_{2} x+q_{2} y+r_{2}
\end{aligned}
$$

The entire system architecture consists of five layers, namely, fuzzification layer, product layer, normalized layer, de-fuzzification layer and total output layer.

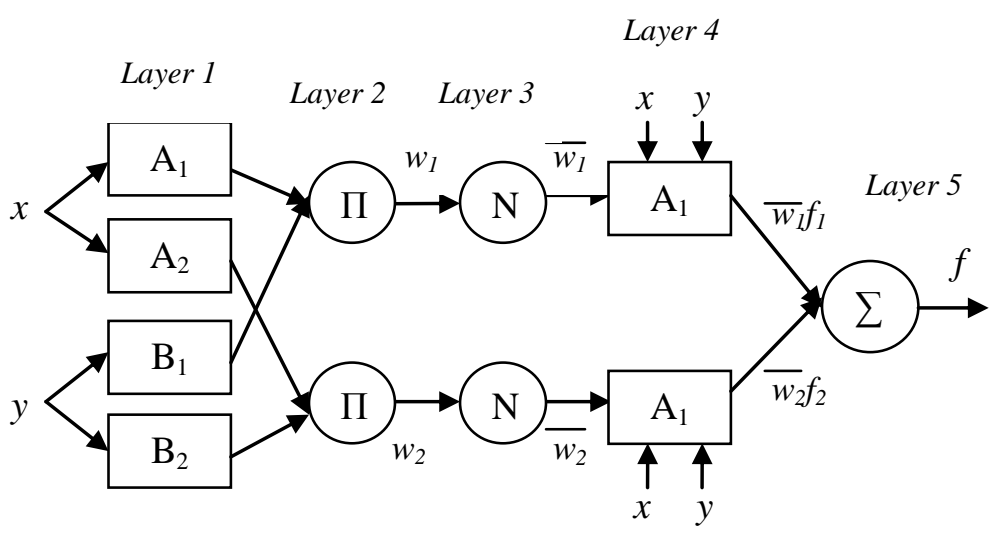

Fig. 1. Schematic diagram of ANFIS

[Layer1]: Every node $\mathrm{i}$ in this layer is an adaptive node with a node function

$O_{1, i}=\mu A_{i}(x), \mathrm{i}=1,2$
$O_{1, j}=\mu B_{j-2}(y), \mathrm{j}=3,4$

Where $\mathrm{x}$ (and $\mathrm{y}$ ) is the input to node $\mathrm{i}$ and $\mathrm{Ai}$ (and $\mathrm{Bj}$ ) is a linguistic label (such as "small" or "large") associated with this node. O1,i is then the membership grade of a fuzzy set A (= A1, A2, B1 and B2). Gaussian parameterized membership function is usually used as the input membership function which guarantees a smooth transition between 0 and 1 :

$\mu A(X)=\exp \left\{-\left(\frac{x-c_{i}}{a_{i}}\right)^{2}\right\}$

Where $\left\{a_{i}, c_{i}\right\}$ is the parameter set.

[Layer 2]: The output of this layer is the product of all the incoming signals and represents the firing strength of a rule:

$O_{2, i}=\omega=\mu A_{i}(x) \times \mu B_{i}(y), \mathrm{i}=1,2$

[Layer 3]: The outputs of this layer are the normalization of incoming firing strengths:

$O_{3, i}=\bar{\omega}=\frac{\omega_{i}}{\left(\omega_{1}+\omega_{2}\right)}, \mathrm{i}=1,2$

[Layer 4]: Every node $\mathrm{i}$ in this layer is an adaptive node with a node function.

$O_{4, i}=\bar{\omega}_{i} f_{i}=\bar{\omega}\left(\mathrm{p}_{i} x+q_{i} y+r_{i}\right)$

Where $\bar{\omega}$ is a normalized firing strength from layer 3 and $\left\{p_{i}, q_{i}, r_{i}\right\}$ is the parameter set of this node. Linear parameters in this layer are referred to as consequent parameters.

[Layer 5]: The single node in this layer computes the overall output as the summation of all incoming signals: 
$O_{5, i}=\sum \bar{\omega}_{i} f_{i}$

There are two adaptive layers (the first and the fourth one) with square nodes in this ANFIS architecture. In the first layer, there are two modifiable parameters $\left\{a_{i}, c_{i}\right\}$ which are related to the input membership functions; these are the so-called premise parameters. There are three more modifiable parameters in the fourth layer $\left\{p_{i}, q_{i}, r_{i}\right\}$ pertaining to the first-order polynomial; these are socalled consequent parameters.

In ANFIS model both structure and parameter learning are performed. In ANFIS model, parameter learning techniques that uses a hybrid learning algorithm is applied to tune the membership functions.

Given the values of premise parameters, the overall output can be expressed as linear combinations of the consequent parameters. More precisely, Jang [20] proposes that the overall output of the ANFIS model can be written as:

$f=\sum f_{i}=\frac{w_{1}}{w_{1}+w_{2}} f_{1}+\frac{w_{2}}{w_{1}+w_{2}} f_{2}=\overline{w_{1}} f_{1}+\overline{w_{2}} f_{2}$

$=\left(\overline{w_{1}}\right) p_{1}+\left(\overline{w_{1}}\right) q_{1}+\left(\overline{w_{1}}\right) r_{1}+\left(\overline{\left.w_{2}\right)} p_{2}+\left(\overline{w_{2}}\right) q_{2}+\left(\overline{w_{2}}\right) r_{2}\right.$

The above-mentioned nonlinear and linear parameters in premise and consequent parts are adjusted by a hybrid learning algorithm, based on a collection of process data.

\subsection{Logistic regression model}

The logistic regression is a statistical model to distinguish two groups based on some distinguishing variables and has been used in studies of classification, especially in bankruptcy prediction domain $[22,23]$. The logistic regression with a dichotomous dependent variable can be expressed in terms of logit or probability form [24]. From the logistic regression model, the estimated values of the dependent variable (which lie between 0 and 1) can be interpreted as the predicted probability of bankruptcy occurring [24]. In logit model, the "odds" is defined as the ratio of the probability of going bankrupt to not going bankrupt or $\mathrm{P}(\mathrm{B}) /(1-\mathrm{P}(\mathrm{B}))$. Logit model is specified as a linear function of the firm's independent variables.

\subsection{Independent sample T-statistic}

T-statistic, introduced in 1908 by William Sealy Gosset, can be used to statistic the statistical significance of the difference between two independent or unpaired samples.

The independent T-statistic method which is considered as a filtering feature selection method in prediction domain, determines whether the mean of a set of samples is significantly greater or less than the mean of another set of samples. In bankruptcy prediction problem, T-statistic technique is commonly used to test the significance between means of bankrupt and non-bankrupt firms for a specific financial ratio. Then, it proposes the variable as a predictive variable when significant difference exists. In this study we set level of significance equal to $99 \%$.

\section{PROPOSED MODEL}

As mentioned in section 1, we decide to compare ANFIS and LR performance by two subset of financial ratios are achieved from examining literature and T-statistic method. The schematic view of proposed procedure for estimating bankruptcy has been shown in Fig .2. Considering steps of proposed model showing in Fig.2, we have three main steps to accomplish bankruptcy prediction.

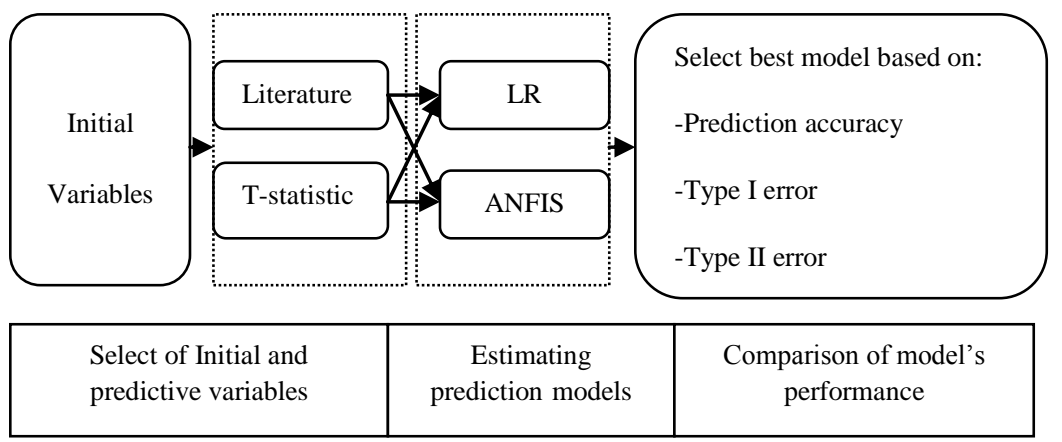

Fig. 2 .The steps toward proposed model

\section{APPLICATION AND DISCUSSION}

\subsection{Sample selection}

This study decides to estimate the bankruptcy prediction model with the financial data of one year prior to financial distress. The dataset consists of non financial firms that are listed on the Tehran Stock Exchange (TSE). The financial institutions have special and different operating and laws [25]; therefore they are excluded from our dataset. Besides, those firms with missing at least one financial ratio value are also dropped from our sample. As the result, the sample includes 68 bankrupt firms from 1997 through 2008. Since we are going to use matched paired data construction, 68 healthy firms are collected in the same time period and industry as the selected bankrupt firms. Therefore, the resulting sample consists of 136 firms.

\subsection{Selection of initial and predictive variables}

In this study, 25 variables were selected as initial variables which are extensively used in the bankruptcy prediction literature as stated by Ravi Kumar and Ravi [18]. Moreover, these financial ratios were chosen based on availability of necessary data of TSE. Table 1 represents these 25 initial financial ratios.

We select the most frequently used variables through the following process. First, we determine the number of times that each variable has been applied in the reviewed studies. Then, we select 6 financial ratios which are applied in $32,22,23,19,18,17$, studies, respectively, and are adjusted with economical situation of Iran. This frequent subset of variables is called Common variables. On the other hand, by using T-statistic 11 predictive variables that have been significant at $99 \%$ are selected. Table 2 represents the variables selected by each method we just mentioned.

Table1. Initial financial ratios

\begin{tabular}{llllll}
\hline$\#$ & Variables & $\#$ & Variables & $\#$ & Variables \\
\hline 1 & EBIT/Total asset & 10 & Sales/equity & 18 & sales/total assets \\
2 & $\begin{array}{l}\text { Net income/total } \\
\text { assets }\end{array}$ & 11 & Total debt/equity & 19 & sales/Cash \\
3 & Net income/Sales & 12 & Total debts/total assets & 20 & sales/Working
\end{tabular}




\begin{tabular}{|c|c|c|c|c|c|}
\hline & & & & & capital \\
\hline 4 & Cash/total assets & 13 & $\begin{array}{l}\text { Current assets/current } \\
\text { debts }\end{array}$ & 21 & $\begin{array}{l}\text { sales/Current } \\
\text { assets }\end{array}$ \\
\hline 5 & $\begin{array}{l}\text { Current assets/total } \\
\text { assets }\end{array}$ & 14 & $\begin{array}{l}\text { Quick assets/current } \\
\text { debts }\end{array}$ & 22 & $\begin{array}{l}\text { long term debt/ } \\
\text { equity }\end{array}$ \\
\hline 6 & $\begin{array}{l}\text { Quick assets/total } \\
\text { assets }\end{array}$ & 15 & equity/total asset & 23 & $\begin{array}{l}\text { net income/ } \\
\text { gross profit }\end{array}$ \\
\hline 7 & $\begin{array}{l}\text { Working capital/ } \\
\text { total assets }\end{array}$ & 16 & Cash/current debts & 24 & cash/ total debt \\
\hline 8 & Size(Log total asset) & 17 & Current debts/total debt & 25 & $\begin{array}{l}\text { sales/ quick } \\
\text { asset }\end{array}$ \\
\hline & $\begin{array}{l}\text { retained earning/ } \\
\text { total asset }\end{array}$ & & & & \\
\hline
\end{tabular}

Table 2. Selected variables by each feature selection procedure

\begin{tabular}{ll}
\hline \multicolumn{1}{c}{ Feature selection method } & Selected variables \\
\hline Independent sample & EBIT/Total asset, Net income/total asset \\
t-statistic & Net income/Sales, Cash/total assets, \\
& $\begin{array}{l}\text { Total debt /equity, Total debts/total assets, } \\
\text { Current assets/current debts, Quick assets/ } \\
\text { current debts, equity/total asset, Cash/ } \\
\text { current debts, cash/ total debt } \\
\\
\text { EBIT/Total asset, Net income/total assets, } \\
\text { Working capital/total assets, sales/total assets, } \\
\text { retained earning/total assets, Current assets/current } \\
\text { debts }\end{array}$ \\
\hline
\end{tabular}

\subsection{Estimation ANFIS and LR prediction models}

Prediction models, usually the entire data set is arbitrary divided into two subsamples: a training subsample and a testing subsample. The training subsample is used to estimate the model; however, the testing subsample is employed to assess the model's predictive capability.

Since, the size of training and testing samples may influence the predictive ability of the models, three data partitions are applied. The considered three data partitions by a random sampling | procedure are:

a. 90/10 partition: "training" (122 firms: 61 bankrupt and 61 healthy) and "testing" (14 firms: 7 bankrupt and 7 healthy).

b. 80/20 partition: "training" (109 firms: 55 bankrupt and 54 healthy) and "testing" (27 firms: 13 bankrupt and 14 healthy).

c. 70/30 partition: "training" (96 firms: 48 bankrupt and 48 healthy) and "testing" (40 firms: 20 bankrupt and 20 healthy).

Subsequently, the model is estimated and its predictive capabilities are examined using each of the above partitioned subsample. It is to be emphasized that in order to avoid significant unlearning, as [13] points out, the data set used to train the network should contain some of both bankrupt and healthy firms in a random order. Using For grid partition method we set 2 Gaussian Bell shape membership function for each variable. Characteristics of each structure of FIS are summarized in Table 3. two methods for feature selection and three data partitioning procedure, 12 different models with ANFIS and LR models are estimated.

For generating network structure of ANFIS two method has been proposed: grid partition and subtractive clustering techniques [20]. We apply the clustering technique to estimate common-ANFIS models and grid partition technique for estimating T-test-ANFIS models. The parameters of subtractive clustering generating method are the range of influence, squash factor, accepts ratio, and rejection ratio which should be predetermined before the training procedure. The values of all parameters are set at their default values except for the range of influence which is set to be 0.01 . In addition, the Gaussian Bell shape membership function will be chosen as a default membership function for each input variable.

Table 3. The considered parameter of proposed ANFIS model

\begin{tabular}{lllllll}
\hline $\begin{array}{l}\text { Structure of } \\
\text { FIS }\end{array}$ & $\begin{array}{l}\text { Range } \\
\text { influence }\end{array}$ & $\begin{array}{l}\text { MF } \\
\text { type }\end{array}$ & $\begin{array}{l}\text { Train } \\
\text { method }\end{array}$ & $\begin{array}{l}\text { Epoch } \\
\text { Error } \\
\text { Tolerance }\end{array}$ & $\begin{array}{l}\text { Number } \\
\text { Of MF }\end{array}$ \\
\hline $\begin{array}{l}\text { Sub. } \\
\text { Clustering }\end{array}$ & 0.01 & $\begin{array}{l}\text { Gaussian } \\
\text { shape }\end{array}$ & hybrid & 5 & 0 & - \\
Grid partitic - & $\begin{array}{l}\text { Gaussian hybrid } \\
\text { Bell shape }\end{array}$ & 5 & 0 & 2 \\
\hline
\end{tabular}

Common-LR and T-statistic-LR models are also estimated for three partitioning data patterns. The statistical results shows that all of the estimated LR models are meaningful, however, some of financial ratio's coefficients are not significant.

The classification of a firm is determined by a cutoff value which is set to balance Type I and Type II errors. A firm with a predicted value greater than this cutoff value is considered as bankrupt, otherwise a healthy firm [25]. We assume the costs of Type I error and Type II errors are equal and the value of cutoff is 0.5 . It means that if the estimated output is greater than 0.5 , the firm would be predicted as bankrupt.

\subsection{Assessment and comparison of model's performance}

In this section, the detailed comparison of the constructed models is accomplished. In order to compare of model's performance, prediction accuracy, Type I error and Type II error which are wellknown performance measures in bankruptcy prediction problem are used.

Prediction accuracy can be computed as the percentage of the firms that are correctly classified to the healthy or bankrupt firms. This concept is a widely used measure of predictive accuracy [26]. Type I error occurs when a healthy firm is incorrectly classified as a bankrupt firm and Type II error occurs when a bankrupt firm is being classified as a healthy firm.

Since, Type I error is more critical than Type II error in bankruptcy prediction problem [27], models with higher prediction accuracy (least Type I error) are preferred.

The classification results of both training and hold-out samples for ANFIS and LR models for three partitioning data patterns are presented in table 4, 5 and 6 . Table 7 gives the average classification 
performances of different classification methods for both training and test sample in three data partition patterns. The values in parentheses are standard deviations corresponding to individual classification results.

Table 4. Performance of classification models for $90 / 10$ data partition method: in percentage

\begin{tabular}{lllll}
\hline Data set & Models & $\begin{array}{l}\text { Prediction } \\
\text { accuracy }\end{array}$ & $\begin{array}{l}\text { Type I } \\
\text { error }\end{array}$ & $\begin{array}{l}\text { Type II } \\
\text { error }\end{array}$ \\
\hline Traininı̨ & Common-ANFIS & 100 & 0 & 0 \\
Tstatistic-ANFIS & 94.26 & 8.19 & 3.27 \\
& Common-LR & 83.61 & 29.78 & 8.7 \\
& Tstatistic-LR & 81.96 & 19.67 & 16.39 \\
Testing & Common-ANFIS & 92.85 & 14.28 & 0 \\
& Tstatistic-ANFIS & 92.85 & 0 & 14.28 \\
& Common-LR & 92.85 & 14.28 & 0 \\
& Tstatistic-LR & 78.57 & 0 & 42.85 \\
& & & \\
\hline
\end{tabular}

Table 5. Performance of classification models for $80 / 20$ data partition method: in percentage

\begin{tabular}{lllll}
\hline Data set & Models & $\begin{array}{l}\text { Prediction } \\
\text { accuracy }\end{array}$ & $\begin{array}{l}\text { Type I } \\
\text { error }\end{array}$ & $\begin{array}{l}\text { Type II } \\
\text { error }\end{array}$ \\
\hline Trainin̨ & Common-ANFIS & 100 & 0 & 0 \\
Tstatistic-ANFIS & 95.41 & 9.25 & 1.81 \\
& Common-LR & 85.32 & 14.54 & 14.81 \\
& Tstatistic-LR & 81.65 & 20.37 & 16.36 \\
Testing & Common-ANFIS & 92.59 & 0 & 15.38 \\
& Tstatistic-ANFIS & 92.59 & 38.46 & 0 \\
& Common-LR & 88.88 & 0 & 14.81 \\
& Tstatistic-LR & 66.67 & 28.57 & 38.46
\end{tabular}

Table 6. Performance of classification models for 70/30 data partition method: in percentage

\begin{tabular}{cllll}
\hline Data set & Models & $\begin{array}{l}\text { Prediction } \\
\text { accuracy }\end{array}$ & $\begin{array}{l}\text { Type I } \\
\text { error }\end{array}$ & $\begin{array}{l}\text { Type II } \\
\text { error }\end{array}$ \\
\hline Trainin̨ & Common-ANFIS & 100 & 0 & 0 \\
Tstatistic-ANFIS & 93.75 & 8.3 & 4.2 \\
Common-LR & 82.39 & 18.75 & 16.67 \\
& Tstatistic-LR & 80.21 & 25 & 14.58 \\
Testing & Common-ANFIS & 92.5 & 10 & 5 \\
Tstatistic-ANFIS & 90 & 10 & 10 \\
Common-LR & 90 & 10 & 10 \\
Tstatistic-LR & 85 & 15 & 15 \\
& & & \\
\hline
\end{tabular}

Table 7. Average Performance of classification models: in percentage

\begin{tabular}{llll}
\hline Models & Prediction accuracy & $\begin{array}{l}\text { Type I } \\
\text { error }\end{array}$ & $\begin{array}{l}\text { Type II } \\
\text { error }\end{array}$ \\
\hline
\end{tabular}

\begin{tabular}{llll}
\hline Common-ANFI & $96.28(4.08)$ & $4.04(6.41)$ & $3.39(6.2)$ \\
Tstatistic-ANFI & $93.75(1.84)$ & $8.3(13.29)$ & $4.2(5.43)$ \\
Common-LR & $82.39(4.05)$ & $18.75(9.82)$ & $16.67(6.14)$ \\
Tstatistic-LR & $80.21(6.41)$ & $25(10.02)$ & $14(13)$ \\
\hline
\end{tabular}

From tables 4-7 the following conclusions are obtained:

(1) Analysis of our results recommend ANFIS model as a capable and appropriate method for bankruptcy prediction of TSE' firms. This model has predictive accuracy more than $90 \%$ in all constructed models based on different partitioning data. This prediction performance can be considered one of the best results of previous literature.

(2) ANFIS outperforms LR in both training and test samples in all partitioning patterns. According to tables 5, 6 and 7, ANFIS model has the best performance based on the prediction accuracy. However, it has less superior performance based on the type I error and type II errors. As shown in table 7, ANFIS models performs better than LR models in classifying the firms into bankrupt and non-bankrupt, with average prediction accuracy of $96.27 \%$ and $93.75 \%$ and least type I and type II errors.

(3) The classification models constructed based on Common variables perform better than those constructed based on $\mathrm{T}$ statistic variables. Table 7 indicates Common-ANFIS and Common-LR have higher prediction accuracy and lower Type I error in comparison with T-statistic-ANFIS and T-statisticLR models. So it can be concluded that the more frequent variables in the literature yield better prediction performance than statistical based feature subset selection.

(4) The common-ANFIS model is superior to other classification methods. This model has highest Prediction accuracy, least Type I error and type II error. In all the data sets, this model correctly classifies all firms in the train set into their groups and has average prediction accuracy of $96.27 \%$. From the correct classification ratios in tables 5, 6 and 7, we can see that T-statistic-LR model provides the worst results with average prediction accuracy of $80.21 \%$.

Figures 3 and 4 depict the schematic comparison of the performance of the models. Superiority of common-ANFIS model to the other models is apparent based on all prediction performance measures. Fig. 3. (a) Shows prediction accuracy of the models for both training and test sample and 90/10, 80/20 and 30/70 data partitioning patterns. According to this graph Common-ANFIS model appears to be the best. Fig. 3. (b) and Fig. 3. (c) represent the models performance based on Type I and Type II error. As we can see from these two graphs, ANFIS-Common model still represents the best performance, followed by T-statistic-ANFIS in the second best model. Finally, the comparison between average performances of all models has been shown in Fig. 4. This figure indicates that Common-ANFIS model has the highest average prediction accuracy and the least Type I and Type II error. 


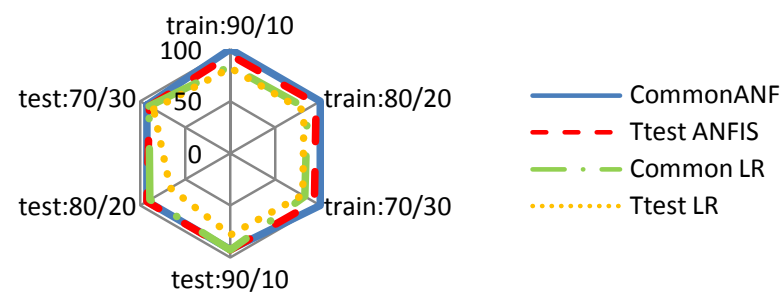

(a)

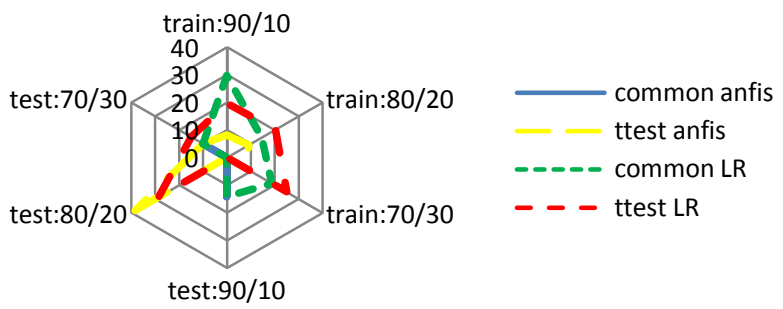

(b)

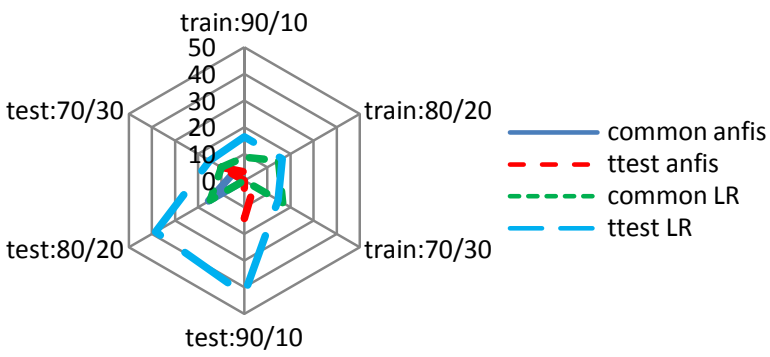

(c)

Fig. 3. Graphical Performance of classification models. (a) Prediction accuracy. (b) Type I error. (c). Type II error

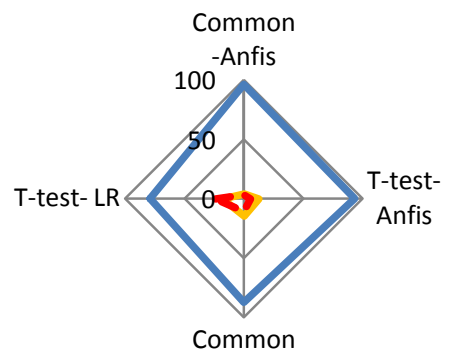

$-\mathrm{LR}$
Fig. 4. Graphical overall Performance of classification models

\section{CONCLUSIONS}

So far, a few studies has applied ANFIS model for bankruptcy prediction. To address the lack of empirical researches in this topic, in this paper we apply ANFIS model for bankruptcy prediction and compare its performance with logistic regression model. We give a special attention to preprocessing feature selection procedure using T-statistic method and previous literature examining.
Using a dataset of 136 Iranian companies listed on Tehran Stock Exchange (TSE), we evaluate performance of ANFIS in comparison with LR model based on prediction accuracy, Type I error and Type II error. The main results are as follows:

- $\quad$ ANFIS model is superior to LR model.

- Common variables which are the most frequent variables in the literature present better prediction performance than statistical based feature subset selection method.

Some suggestions for future studies could be developing a more accurate ANFIS model by examining the pattern and number of membership functions and aggregating ANFIS model with other statistical or artificial intelligent techniques in order to improve prediction accuracy.

\section{REFERENCES}

[1] J. Jones, D.A. Hensher, Advances in Credit Risk Modelling and Corporate Bankruptcy Prediction. Cambridge University Press, First published in print format (2008).

[2] W.H. Beaver, Financial ratios predictors of failure, Journal of Accounting Research (1996), pp.71-111.

[3] E. J. Altman, Financial ratios, discriminant analysis and the prediction of corporate bankruptcy. Journal of Finance 23(4) (1968),pp. 589-609.

[4] P.A. Myer, H.W. Pifer, Prediction of bank failure, Journal of Finance (1970) 853-868.

[5] J. Ohlson, Financial ratios and the probabilistic prediction of bankruptcy, Journal of Accounting Research 18(1) (1980), pp. 109-131.

[6] F.M. Tseng, Y.Ch. Hu, comparing four bankruptcy prediction models: Logit, quadratic interval logit, neural and fuzzy neural networks, Expert System with Application 37 (2010), pp. 1846-1853.

[7] S. Cho, J. Kim, J. Kwon Bae, An integrative model with subject weight based on neural network learning for bankruptcy prediction, Expert Systems with Applications 36 (2009), pp. 403-410.

[8] L. Salchenberger, E. Minecinar, N.A. Lash, Neural networks: A new tool for predicting thrift failures, Decision Science 23 (1992), pp. 899-916.

[9] D. Fletcher, E. Goss, Forecasting with neural networks, Information and Management 24 (1993), pp. 159-167.

[10] P. Coast, F. Fant, Recognizing financial distress patterns using a neural network tool, Financial Management 22(3) (1993), pp. 142-155.

[11] Y. Yoon, T. Guimaraes, G. Swales, Integrating neural networks with rule-based expert systems, Decision Support Systems 11 (1994), pp. 497-507.

[12] A. F. Atiya, Bankruptcy prediction for credit risk using neural networks: A survey and new results, IEEE Transactions on Neural Networks 12(4) (2001), pp. 929935.

[13] R. Malhotra, D.K. Malhotra, Differentiating between good credits and bad credits using neuro-fuzzy systems. 
European Journal of Operational Research 136 (2002), pp. 190-211.

[14] O. Purvinis, R. Virbickait e, P. Sukys, Interpretable Nonlinear Model for Enterprise Bankruptcy Prediction, Nonlinear Analysis: Modeling and Control 13(1) (2008), pp. 61-70.

[15] L. Zadeh, Fuzzy Sets, Inf. Control 8 (1965) 338-353.

[16] P. Ravi kumar, V. Ravi, Bankruptcy prediction in banks by fuzzy rule based classifier. In: Proceedings of the 2006 first international conference on digital information management (2006), pp. 222-227.

[17] P. Ravi kumar, V. Ravi, Bankruptcy prediction in banks by an ensemble classifier. In: Industrial technology, IEEE International Conference on ICIT (2006), pp. 2032-2036.

[18] P. Ravi Kumar, V. Ravi, Bankruptcy prediction in banks and firms via statistical and intelligent techniques - A review, European Journal of Operational Research 180 (1) (2007), pp. 1-28.

[19] S. Chokri, Fuzzy neural model for bankruptcy prediction, The Business Review (2007).

[20] J.S.R. Jang, ANFIS: Adaptive-Network-Based Fuzzy Inference System, IEEE Transactions on Systems, Man, and Cybernetics 23(3) (1993), pp. 665-685.
[21] C.F. Tsai, Feature selection bankruptcy prediction, Knowledge-Based Systems 22(2) (2009), pp. 120-127.

[22] J. B. Thomson, Predicting bank failures in the 1980s. Federal Reserve Bank of Cleveland Economic Review 27 (1991), pp. 9-20.

[23] J. Kolari, D. Glennon, H. Shin, M. Caputo, Predicting large US commercial bank failures, Journal of Economics and Business 54(321) (2002), pp. 361-387.

[24] T.F. Liao, Interpreting probability models: logit, probit, and other generalized linear models. Sage Publications, Thousand Oaks, CA., (1994)

[25] T. H. Lin, A cross model study of corporate financial distress prediction in Taiwan: Multiple diccriminant analysis, logit, probit and neural networks models. Neurocomputing, 72 (2009), pp. 3507-3516.

[26] C.B. Cheng, C.L. Chen, C.J. Fu, Financial distress prediction by a radial basis function network with logit analysis learning, Computers \& Mathematics with Applications 51 (34) (2006), pp. 579-588.

[27] A. Aziz, A. Humayon, Corporate bankruptcy: where we stand? Corporate Governance 6 (2006), pp.18-33. 